International Review of Research in Open and Distributed Learning Volume 16, Number 6

November - 2015

\title{
A Strategic Response to MOOCs: How One European University is Approaching the Challenge
}

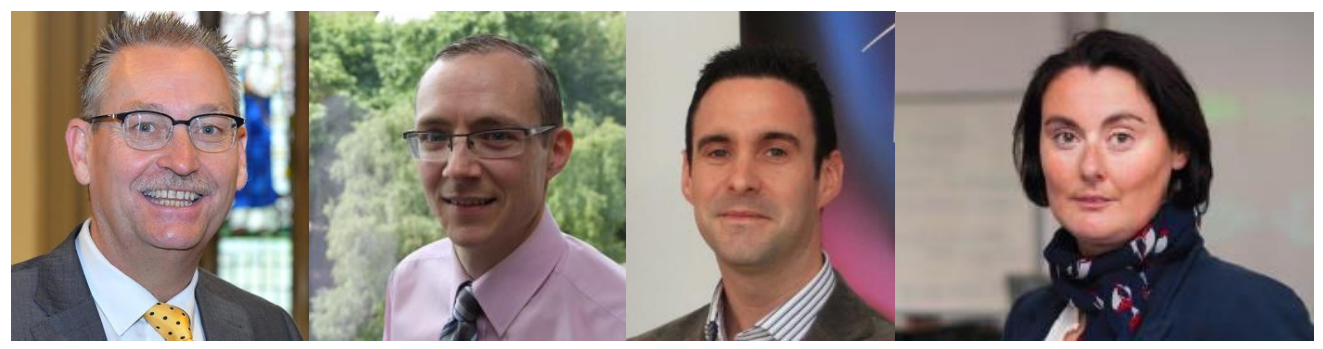

Mark Brown, Eamon Costello, Enda Donlon and Mairead Nic Giolla-Mhichil National Institute for Digital Learning, Dublin City University

\begin{abstract}
This paper briefly outlines some of the macro level claims, counter-claims, and unresolved debates surrounding the rapid growth of Massive Open Online Courses (MOOCs) in Higher Education. It then reports insights, experiences, and perceptions of those charged with developing a strategic institutional response to the challenges and opportunities presented by the MOOC movement framed within a wider European context. A description of the key drivers, strategic deliberations, and major decision points in micro-level MOOC related discussions at Dublin City University (DCU) is provided along with brief analysis of the advantages and disadvantages of a range of platform options. In critically reflecting on the burgeoning MOOC literature in the context of this single institution experience, the paper aims to demonstrate the value of aligning key decisions with well-defined institutional drivers, which in turn are used to help review and evaluate the technical and pedagogical affordances of different MOOC platforms. Finally, a number of strategic questions are presented that may help guide future decisions about the adoption of MOOCs by other institutions.
\end{abstract}

Keywords: Massive Open Online Courses, European, Strategic Drivers, Platforms 


\section{Introduction}

Massive Open Online Courses (MOOCs) are being touted as the latest panacea for higher education. There have been many bold claims made about the promise as well as the perils of the MOOC movement (Krause \& Lowe, 2014; Sharrock, 2015). Despite predictions that online learning is an avalanche on the edge of transforming higher education (Barber, Donnelly \& Rizvi, 2013; Brown, 2015), the legitimacy of the MOOC as an educational innovation is primarily derived from its association with high status, élite universities (Selwyn, Bulfin \& Pangrazio, 2015). In this regard, the MOOC is perceived by many sceptics as simply a clever marketing ploy by some of the world's top universities to reinforce the value of traditional face-to-face teaching where students get a real education (Krause \& Lowe, 2014). The predominant role of elite universities in promoting MOOCs is why critics such as Barlow (2014) argue the movement may be just another neo-colonialist tool reproducing privilege.

On the one hand, there is no disputing the fact that the abundance of information now available on the Internet is challenging the privileged nature of traditional academic knowledge that historically has been protected by universities. Furthermore, online learning through new forms of massive pedagogy has the potential to reduce costs, enhance the quality of educational resources, and address the growing demand for higher education. On the other hand, the inconvenient truth is that MOOCs have yet to deliver on the promise of radically opening up access to higher education, especially in developing nations. Far from being a disruptive game changer, the vast majority of learners who complete MOOCs are already well educated people living in the developed world (Macleod, Haywood, Woodgate, \& Alkhatnai, 2015). Although we need to go beyond simple binary arguments, the key point is that the long-term impact of MOOCs on higher education remains the subject of considerable debate.

It also needs to be noted that relatively few universities currently offer free online courses. According to Allan and Seaman (2015), the proportion of Colleges offering MOOCs in United States (US) is around 8.0\%, although this figure is up from 5.0\% in 2014 and $2.6 \%$ in 2013. They also report that in 2013 the majority of US higher education institutions (53\%) were still undecided about whether to develop MOOCs (Allan \& Seaman, 2014). Notably, by 2014 the undecided number had fallen to 40\% (Allan \& Seaman, 2015). In 2013, one-third (33\%) of institutions had no plans in this area, with this figure having increased to $46 \%$ in the 2014 survey (Allan \& Seaman, 2015). Notably, in 2013 Allan and Seaman (2014) report that only 23\% of academic leaders who responded to the survey believe that MOOCs represent a sustainable model for offering online courses, which has further reduced to just $16 \%$ in the 2014 results (Allan \& Seaman, 2015). What the above findings indicate, arguably, is that most Colleges, at least in the U.S., are no longer sitting on the sideline of the MOOC frenzy. Only a relatively small percentage of institutions have joined the movement and an increasing number appear to have no plans to adopt MOOCs in the future.

This work is licensed under a Creative Commons Attribution 4.0 International License. 
In the case of European universities, there is less mature data on their strategic response to MOOCs. It is generally accepted, nevertheless, that Europe has been much slower than the US to embrace the potential of new models of online learning, with some notable exceptions such as the UK Open University through FutureLearn and the European Commission funded OpenUpEd initiative. While the number of MOOCs being offered is steadily growing in Europe, evidenced by tracking data published by the European MOOC Scoreboard (Open Education Europa, 2015), it is likely that most universities are still deliberating on the phenomenon or at the early stages of developing an appropriate institutional response. At a macro-level the best indicator we have the MOOC movement has not yet peaked in Europe comes from a recent European survey, which indicates that $71 \%$ of responding institutions offer, or plan to offer, free online courses in the future (Jansen \& Schuwer, 2015).

At a micro level, the findings of this survey accurately reflect the situation at Dublin City University (DCU), where at the beginning of 2015 no firm commitment had been made to embark on a specific MOOC initiative. That said, there was strong intent as a modern, digital-era university with a $21^{\text {st }}$ Century outlook to go beyond being a passive observer of the MOOC movement. To this end, DCU was actively participating in two European funded MOOC projects (HOME \& SCORE 2020) and over the last 18 months had been identifying key internal drivers relevant to the most appropriate strategic response. In parallel to this work, the University had been evaluating a range of MOOC platforms that were perceived offer the best strategic fit for any future initiative. Drawing on the experience of those leading these DCU initiatives, and efforts to promote greater critical debate more generally about the impact of MOOCs on the future of higher education, the purpose of this case study is to share an insider's perspective on the deliberations within this single institution. More specifically, we set out to offer insights from this micro level experience into our analysis of the strategic drivers, evaluation of competing MOOC platforms, and the types of questions that should guide discussions, which may be valuable to other institutions in their own deliberation processes.

\section{About DCU}

This section provides a brief description of DCU to situate the case study in both the Irish and wider European context. DCU was founded in 1981 and comprises over 12,000 students. With the current Incorporation Project (known as the "New DCU") involving the merging of three independent Colleges of Education, and the creation of a new fifth Faculty of Education, by the end of 2015 University's student body will increase by another 4000 students.

DCU has a reputation as Ireland's University of Enterprise through it strong, active links with academic, research, and industry partners. Innovation is at the core of its institutional culture, as evidenced by DCU's active member of the European Consortium of Innovative Universities (ECIU). Internationally DCU is ranked 366 in the 2014 QS rankings and has been ranked among the world's best in the QS league table of the world's young universities - QS World Top 50 under 50 University Rankings (ranked 44 in 2013). In 2015, DCU hosted the Times Higher Education 
Young Universities Summit and was ranked $75^{\text {th }}$ in universities around the world under 50 years of age. The above rankings serve to confirm that in a wider European context DCU is very much a contemporary university with a short history but strong ambition and institutional ethos of being a future-maker on the international stage.

It is important to note that DCU has offered distance education for over 30 years and previously hosted the National Distance Education Centre, which later became known as Oscail. The term Oscail translates to "Open Learning" in the Irish language and reflects DCU's strong commitment to extending access to higher education through more flexible models of learning. While the funding model for higher education in Ireland heavily favours full-time, campus-based learners, with limited government assistance for part-time distance learners, each faculty currently offers online programmes with approximately $10 \%$ of DCU's total student population studying offcampus.

The University continues to play a leading role nationally in the provision of distance and online education, evidenced by the establishment in November 2013 of the National Institute for Digital Learning (NIDL). The NIDL has a vision of being recognised as a world leader at the forefront of education, research, and innovation in contemporary models of teaching and learning that help to transform lives and societies. Notably, the Institute hosted Ireland's first National MOOC Symposium in May 2015 and a few weeks later launched, in partnership with the Irish Learning Technology Association (ILTA), Ireland's first Horizon Report on future trends facing higher education (Johnson, Adams Becker, Cummins, Estrada, \& Freeman, 2015).

Lastly, the goal of widening access to higher education through the development of a 21st Century Digital Campus is a stated goal and core feature of DCU's Strategic Plan. Transforming Lives and Societies (2013-2017) (DCU, 2012) provides a strategic framework for significant growth in the provision of open, online, and blended learning across all faculties. Importantly, this growth is being led by a strong pedagogical focus as DCU endeavours to offer a more interactive, collaborative, media rich, and personalised learning experience. Equally of importance in the context of MOOCs is that the emphasis on widening access and promoting new flexible models of learning through digital technology is entirely consistent with DCU's (2012) overarching mission of Transforming Lives and Societies through Education, Research and Innovation. In other words, there is a synergy between DCU's institutional mission and the opportunities that MOOCs provide for opening up education.

\section{Strategic Drivers}

In the absence of a clear or sustainable business model, why would any higher education institution contemplate launching a MOOC initiative? Allen and Seaman (2014) report the two most cited reasons for introducing MOOCs are marketing-related: (i) to "increase the visibility of the institution" and (ii) to "drive student recruitment." Interestingly, universities with the most extensive traditional online offerings were also those most likely to say that they are embracing

This work is licensed under a Creative Commons Attribution 4.0 International License. 
MOOCs to "increase the visibility of the institution." In contrast, Colleges with no current online offerings report MOOCs will be used to "drive student recruitment" (Allen \& Seaman, 2014). Over one-third of institutions with current or planned MOOCs cited reasons related to course design issues, including a desire to "experiment with innovative pedagogy" or "provide more flexible learning opportunities." Relatively speaking, Allen and Seaman (2014) found there was less support for other goals, such as "reaching new students," "supplementing on-campus" activities, potential "cost reductions," "learning about scaling," and "generating income."

Holland and Tirthali (2014) report a similar trend from interviews with 83 educational leaders across a range of predominantly US-based institutions. Notably, $65 \%$ of institutional leaders report that "extending reach and access" was a key reason for offering MOOCs, followed by $41 \%$ acknowledging the value of "building and maintaining their brand." In addition, they found that "promoting innovation" (38\%) and "improving educational outcomes" (38\%) were important factors influencing decisions to develop MOOCs (Holland \& Tirthali, 2014). In contrast to Allen and Seaman (2014), the goal of "improving economics" (38\%) (i.e., potential cost savings and/or generating revenue) was identified as an important longer-term goal. Also Holland and Tirthali (2014) report the goal of "supporting research on teaching and learning" (28\%) was a consideration, with a particular emphasis on improving participant engagement and completion rates. Importantly, there appeared to be "less effort on determining whether learners actually gain new skills and knowledge from the courses" (Holland \& Tirthali, 2014, p.11).

The above findings contrast with the aforementioned European survey conducted at the end of 2014 where the institutional objectives for MOOCs appear to relate more to reaching new students and creating flexible learning opportunities rather than driving student recruitment (Jansen \& Schuwer, 2015). However, the objective of increasing "institutional visibility" is common on both sides of the Atlantic and ranks as the primary driver for MOOC initiatives in both the U.S and Europe.

Conor (2014) provides a more detailed analysis of the institutional policy drivers and change dynamics based on the experience of introducing MOOCs in three Australian universities. Through interviews with senior academics and analysis of policy documents, four commonalities were identified from the institutional constructions of MOOCs: (i) the use of e-learning policy was seen as a vehicle for curriculum redesign; (ii) an emphasis on internal curriculum redesign and transformation of the student learning experience was a core rationale for MOOCs; (iii) there was a desire to capitalise on promotional opportunities but at the same time a reticence around wholly embracing the phenomenon; and (iv) the absence of access-driven concerns in university policy despite the prominence of the goal of widening participation in broader public debate about the potential of MOOCs (Conor, 2014). This disconnection from the "extending access mission" that strikes at the core of the new openness movement is explained largely due to:

e-learning policies are being used as instruments to drive broader changes in 
curriculum and curriculum design practices at these institutions, that curriculum leaders see concurrent opportunities for curriculum renewal and institutional promotion in relation to MOOCs, but that they have concerns about what MOOCs represent for the university, and are reluctant to embrace narratives that promote changes to access and traditional enrolment practices (Conor, 2014, p.633).

What this line of case study research illustrates is the value of a more situated analysis of institutional drivers. Surprisingly, beyond the major surveys cited above, there is a significant gap in the literature around the specific institutional drivers that have influenced universities to adopt MOOCs. While no doubt within universities many internal papers have been written to weigh up platform options and make the case for institutional MOOC initiatives, based on a search of major library databases, none of these paper have gone on to be published to offer greater insight into the factors that influence the deliberation process. For example, a search of the EBSCO database using key words such as "MOOC," "Institutional," and "Policy" reveals only a single publication (Figure 1). Given this gap in the literature the remainder of this paper attempts to describe how one institution has approached the challenge of responding to the MOOC movement since the start of 2014.

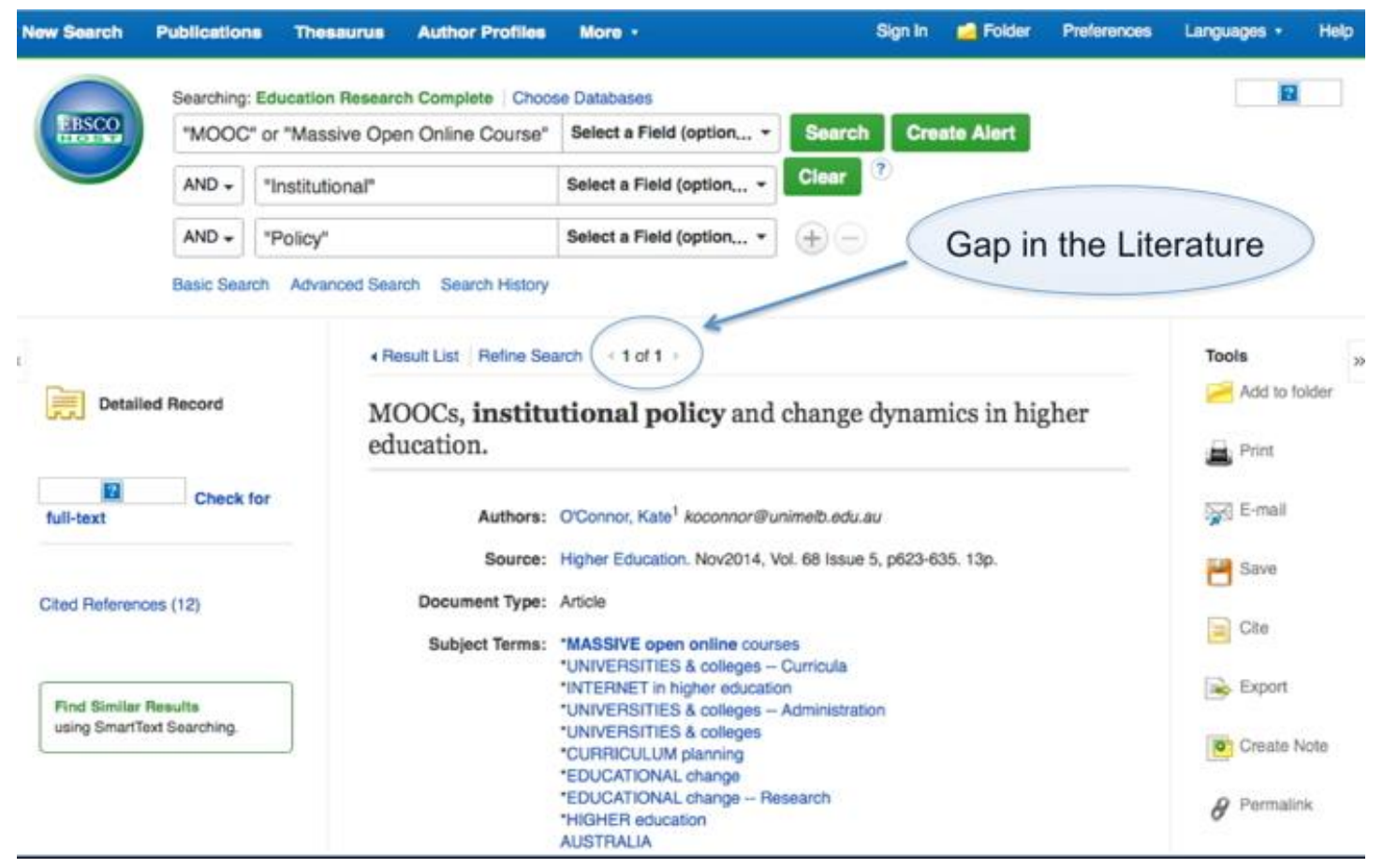

Figure 1. Results of EBSCO search on MOOC policy drivers

\section{Why MOOCs at DCU?}

In the case of DCU, all of the above goals and drivers have been discussed over the last 18 months, 
including the key tension between promoting wider access to higher education to increasingly diverse and geographically dispersed people who might not normally be able to study, whilst enhancing the University's profile and international reputation. In unpacking this tension and analysing the pros and cons of whether or not to develop MOOCs, we believe there is little doubt that an initiative in this area has potential to enhance DCU's reputation as one of Ireland's leading online/distance education providers. Moreover, a well-developed MOOC programme on the right platform might help to position DCU as a global player in this burgeoning area. After all, as shown by Allan and Seaman (2015), very few US universities have launched MOOC initiatives and proportionally the number is probably even less in Europe. Set against the new global higher education landscape, joining a MOOC platform offers the opportunity for DCU to promote our existing online programmes to a wider audience, which may, in turn, help to recruit prospective international students (either on-campus or off-campus) to degree programmes in key areas of world-class research expertise.

The crucial point is that the goal of recruiting new students and enhancing DCU's international reputation for quality are not mutually exclusive from our longstanding tradition of promoting wider access to higher education. All of these drivers are firmly rooted within and articulated throughout DCU's institutional mission of Transforming Lives and Societies.

In this regard any decision to develop MOOCs will be part of a larger strategic development linked to the establishment of the new DCU Connected [http://connected.dcu.ie] brand, which was formally launched in August 2014 (Figure 2). With a strapline of "A quality education wherever you are," the development of a suite of online short courses to extend the University's outreach and reputation alongside our stable of existing online degree programmes, under the umbrella of DCU Connected, is seen as a logical extension of this initiative. 


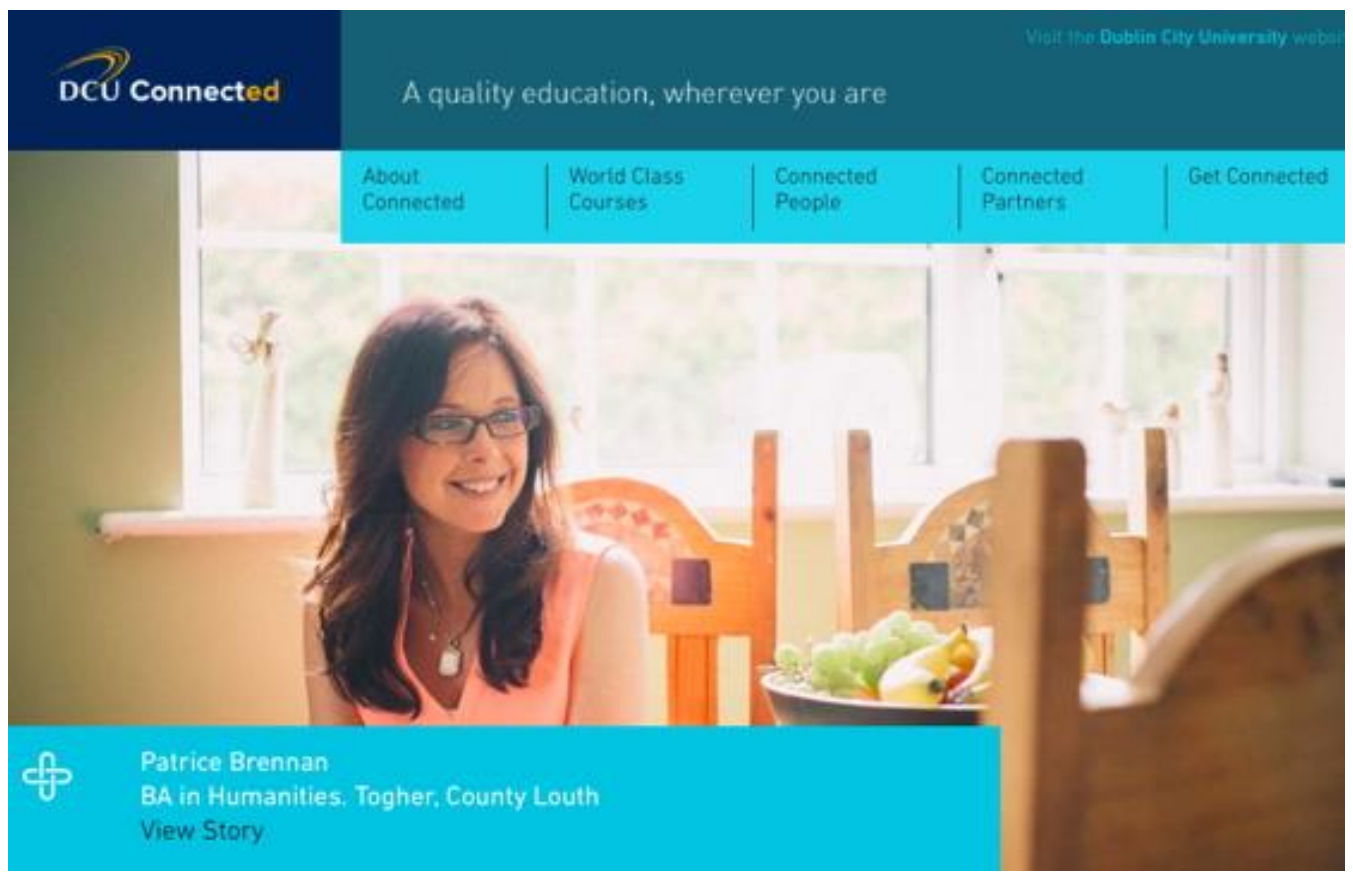

Figure 2. The DCU Connected website

Importantly, the term Connected was deliberately chosen to shift the focus to the learner experience rather than a particular teaching or delivery methodology. We considered the adoption of something more common like DCU Online would be inherently institutionally centric and increasingly passé in today's digital world where online learning is becoming the new normal. Also true to our mission, DCU Connected has a philosophy of working with strategic partners to develop customised, locally relevant, and digitally enhanced courses and programmes for a diverse range of students, irrespective of geographical location. For this reason, DCU Connected incorporates a number of the University's significant transnational activities, including a strategic relationship with Princess Nora Bint Abdul Rahman University in Saudi Arabia, where DCU is contributing to local capability development in a university for women. Another noteworthy partnership is with Arizona State University (ASU), the largest public university in the U.S., where DCU is jointly developing a number of online courses, including a Masters in Biomedical Diagnostics.

In addition to the above high-level strategic drivers, the decision to pursue a MOOC agenda is being significantly influenced by DCU's commitment to a philosophy of Openness and the development of a modern Digital Campus, which enables a culture of innovation and the goal of providing students with a rich $21^{\text {st }}$ Century learning experience (Teaching and Learning Strategy, 2014). More specifically, the MOOC is viewed as part of a wider ecology of innovation (Weller \& Anderson, 2013) that may help with the step change DCU is aiming to achieve through curriculum redesign and increasing capability in new digital pedagogies. In terms of the wider innovation agenda, supported by the NIDL, it needs to be noted that in weighing up different MOOC options 
considerable value is placed on the chance of collaborating in a consortium of institutions in order to benchmark and learn as much as possible from the experience. Hence there is also a research dimension to our interest in MOOCs, which is one of the reasons why we have chosen to play a role in the European funded OpenUpEd initiative.

Lastly, another benefit of developing a suite of MOOCs is the potential they offer in terms of transition education and more particularly first-year retention and learner success. This goal is not something explicitly identified in the aforementioned research on the drivers influencing decisions at other institutions. The focus is a little different as we believe brief online taster courses, which showcase different subjects, may help prospective students to select the right degree programme by gaining a better sense of the discipline and what is required to be successful (Carson, Kanchanaraksa, Gooding, Mulder, \& Schuwer, 2012). Moreover, a free online taster course may help prospective students to better understand the career opportunities from pursuing study in the discipline. Such knowledge is an important factor in shaping programme choice and ultimately student success. In a similar vein, MOOCs are perceived to have potential value in promoting student readiness, especially in terms of understanding how to be an effective online learner.

In summary, DCU Connected provides a contemporary, future-focused, overarching strategic platform that encapsulates the mission of extending access to higher education and transforming lives and societies by harnessing the technical and pedagogical affordances of new digital technologies. It follows that the potential of MOOCs in promoting openness, life-long learning, and increased participation in higher education aligns with DCU's mission. Another primary driver for DCU's interest in MOOCs is around fostering innovation, curriculum renewal and professional development in the areas of online and blended learning in accordance with the stated goals of our Strategic Plan. Following on from this point, through a research and development programme supported by the NIDL, the University is keen to transfer pedagogical lessons from the use of MOOCs to enhancing both the on-campus and off-campus student experience. Finally, MOOCs are also seen to offer potential for DCU to support readiness for university study and successful transitions, particularly for at risk learners.

\section{MOOC Options}

Over the last 18 months the NIDL has been leading debate and discussions around the technical, pedagogical, and strategic affordances of a number of MOOC platforms, which are briefly outlined below.

\section{ALISON}

ALISON, which stands for Advance Learning Interactive Systems Online, is an Irish based initiative that claims to be the world's first and original MOOC platform [http://alison.com]. Founded in 2007, ALISON reports that over 3 million learners have participated in one of their courses, which are offered on behalf of, and in partnership with, a number of major companies, 
including Google, Microsoft, and MacMillan. In this respect the courses offered through Alison tend to be more narrowly work skills and vocationally focused and currently there are no reputable universities using this platform. Therefore, the platform does not offer the type of pedagogical community of users that DCU is looking for in any MOOC initiative. Although the Irish connection and established track record of attracting millions of learners from throughout the world is attractive, for the reasons cited above, ALISON is not well suited to the strategic intentions of DCU.

\section{Open2Study}

Over the course of 2014 several discussions took place with Open Universities Australia (OUA) about joining the Open2Study platform [https://www.open2study.com]. Two options were explored: (a) joining the existing group of mainly Australasian institutions using the platform; or (b) negotiating a license to use or purchase a clean skin version of Open2Study to launch a new Irish/European branded MOOC.

The advantage of the first option is that Open2Study is both technically and pedagogically proven and has a growing base of learners from around the world. Open2Study recently celebrated the milestone of reaching 1 million learners. It might also help DCU to extend its outreach and course offerings to the Southern Hemisphere and, in particular, Asia. Although there are strategic benefits to Open2Study establishing a foothold in Europe, and the related business model is potentially attractive, the consortium of partner institutions is less likely to help DCU foster a culture of innovation around online learning and massive pedagogy. There are obvious geographical constraints and exploring pedagogical innovation does not appear to be a strong feature driving the Open2Study platform.

The second option of taking a lead role in establishing a new Irish/European branded MOOC initiative using the Open2Study software architecture was attractive in terms of DCU's reputation for innovation and leadership in online learning. That said, this option would be significantly more expensive and place the University at greater risk as there would be no guarantee the MOOC platform would attract other European partners-let alone a sufficient following of learners. There is also a question of whether Europe really needs another platform. Without anchor funding from a suitable partner to mitigate the risks, this option was not really considered feasible in the current environment.

\section{FutureLearn}

FutureLearn [https://www.futurelearn.com] was established in December 2012 as a private company wholly owned by The Open University in the United Kingdom (UK). The number of partner institutions has steadily grown and FutureLearn claims to now support over 20 of the best UK and international universities. A notable feature of FutureLearn is the relationship it has established with icons of British cultural heritage, including the British Council, British Library, and British Museum. In the Irish context this strong UK influence is not necessarily an advantage 
and so far FutureLearn has yet to establish a strong U.S. foothold.

Arguably, a major difference between FutureLearn and rival MOOC initiatives is the focus given right from the outset to the principles of effective online pedagogy. The FutureLearn website reports that Diana Laurillard's work on Conversational Frameworks has been influential and the following set of principles guide pedagogical and technical developments: being open, telling stories, provoking conversations, embracing massive, creating connections, keeping it simple, learning from others, celebrating progress, and embracing future learners (Sharples, 2014).

From a technical point of view, FutureLearn appears to have learned lessons from earlier MOOCs. The interface is clean and the platform was developed from the outset to work on mobile devices. FutureLearn claims to have designed courses to fit around life, with short activities and clear goals to encourage progress at a comfortable rate, wherever you are, whenever you want on mobile, tablet, or desktop.

Although two Irish universities--Trinity College and Queens University of Belfast--have already joined FutureLearn, the relatively low cost of membership was attractive to DCU. It combines the latest technical designs for mobile learning with a real depth of thinking around pedagogy along with a strong community of practice amongst partner institutions, which is influenced by the long history of the UK Open University of promoting life-long learning. While DCU was initially proactive in exploring the possibility of joining FutureLearn, whilst keeping other options open, we preceived there was likely to be less potential to influence future developments. Moreover, DCU did not want to simply be a client of FutureLearn where we may be constrained by the range and number of courses we could offer.

\section{OER Universtas}

The OER universitas [http://oeru.org] is a global network of more than 30 universities, colleges and polytechnics collaborating to develop free online courses to provide a unique pathway to formal academic qualifications. The initiative has attracted donor funding from The William and Flora Hewlett Foundation and is supported by UNESCO and the Commonwealth of Learning. The OERu is founded on the principles of outreach and community service and has a mission of using solely Open Educational Resources (OER) to provide free learning pathways to people without access to traditional university entry.

Importantly, the OERu is not a formal academic institution and does not confer degrees or qualifications. A unique feature of the OERu is the intention to develop a scalable system of volunteer student support by using community service learning approaches. The OERu has the legal structure of a registered charity under the umbrella of the Open Education Resource Foundation (OERF), which is hosted at the Otago Polytechnic in New Zealand.

While the principles of outreach and expanding access to higher education align with DCU's mission and the OERu has a credible and growing international community of educators guiding 
its development, a number of questions remain about its regulatory status, ability to accredit programmes, and long-term sustainability in the face of more established MOOC initiatives. Having said that, the OERu remains an interesting option but the opportunity costs of committing valuable resources to this initiative had to be considered at the expense of other MOOC options that may better advance DCU's strategic goals.

\section{Udemy}

Udemy [https://www.udemy.com] is a commercial platform that claims to contain over 18,000 courses. This high number is partly explained by a model that provides very little barrier to entry to providers allowing individual teachers to easily sign up and create their own courses. Course creation is free and Udemy's business model is based around a split share of fees, with courses ranging in price from free or a few (US) dollars to several hundred. The platform stretches the definition of openness and is currently focused on attracting corporate in-house or free-lance trainers whose focus is specific industry skills or talented hobbyist who may be lay experts of a particular topic. No university courses may currently be taken for credit via Udemy and its lack of quality assurance and broad focus make it less attractive for consideration as a reputable MOOC platform. Nonetheless, Udemy is a large and established platform with a strong customer base that has the potential to evolve in different directions. Importantly, it also offers a clean skin version should DCU decide to pursue its own platform.

\section{Iversity}

Iversity [https://iversity.org] claims to work in close cooperation with teachers, universities, and knowledge-based companies to build high-quality free online courses. The stated aim is not to replace the university but to empower individual academics to offer courses in their specialist subjects. In this respect the model is not dissimilar to Udemy where the focus is on providing a portal for courses rather than a MOOC platform for enterprise-wide institutional initiatives. Having said that, because Iversity is based in Europe, it can potentially take advantage of the European Credit Transfer System (ECTS). This means in theory that partner institutions can offer assessment of courses that may lead to ECTS credits, although it is unclear how many course participants actually pursue this option. While the Iversity initiative has European Commission support, as far as MOOC initiatives go, it remains relatively immature and in terms of DCU's requirements does not stack up strongly in comparison to other options.

\section{Tata Group}

In November 2014, a high-level delegation from the Tata Group [http://www.tata.com] visited Ireland to discuss the idea of offering their purpose built digital platform to help make the Country the world's leading provider of online learning. The Tata Group, founded in 1868, is a global enterprise headquartered in India, and comprises over 100 operating companies, with operations in more than 100 countries across six continents. The delegation attracted considerable media interest and met with senior politicians, government officials and university leaders, including the President of DCU. These discussions have continued over 2015 but at this This work is licensed under a Creative Commons Attribution 4.0 International License. 
stage DCU has not made any firm commitments to deploying the Tata platform, although a pilot initiative is likely to take place in 2016.

\section{Open Source Options}

The idea of DCU developing its own MOOC platform has also been considered as several open source options exist, including OpenEdX and Moodle.

An increasing number of well-known universities are using OpenEdX for MOOC delivery the platform has a growing community of users. Of course the maintenance, future development and ongoing sustainability of a locally installed open source MOOC initiative has similar risks to the aforementioned clean skin version of Open2Study. However, there are several providers offering externally hosted installations of OpenEdX, which in theory help to mitigate some of the risks. For this reason in the first half of 2015 DCU piloted the development of a course in OpenEdX and investigated the costs and associated business models for an enterprise-wide MOOC initiative using a hosted OpenEdX solution. This option has a number of advantages and may be pursued in the future as part of a deliberate strategy to ensure that we innovate and learn from initiatives in this space on more than a single platform.

An alternative option is a customisable version of Moodle could be deployed with the advantage that DCU already has considerable experience is using this platform. For example, in May 2015 DCU hosted for the second time the annual UK/Ireland MoodleMoot, and is known in Ireland as a leader in this community. On the other hand, Moodle was not designed as a MOOC platform and is not as mobile friendly. Nevertheless, over 2015 DCU has been involved in high-level discussions with several strategic partners, including Moodle HQ, about the need for a MOOC platform that supports European languages others than English and we expect to pilot a new purpose designed virtual learning environment (VLE) at the start of 2016. .The advantage of this pilot is that any lessons we learn from the experience will be able to help shape future developments of the platform.

\section{OpenUpEd}

DCU is already a "partner in planning" for the European funded OpenUpEd initiative and will be a full partner by the end of 2015 [http://www.openuped.eu]. OpenUpEd reflects a particular philosophy of openness and offers a portal for aggregating MOOCs rather than a technical platform. In contrast to other MOOC initiatives, OpenUpEd values and promotes diversity of design and delivery by supporting courses in different languages and through a variety of platforms. In other words, the distinguishing feature of this initiative is that each partner institution uses its own system rather than a common or purpose built MOOC platform. Although OpenUpEd currently claims to have around 170 courses in 12 different languages, the lack of common software architecture and supporting infrastructure makes this option somewhat problematic. OpenUpEd has, however, an open and explicit Quality Label initiative which is based on existing quality frameworks, namely e-Excellence, draws on the experience of European Open 
and Distance Learning (ODL) institutions, and operates on the principles of openness to learners, digital openness, learner-centeredness, independent learning, media supported interaction, recognition pathways, quality focus, and spectrum of diversity (Rosewell \& Jansen, 2014). At this stage, therefore, DCU remains committed to the OpenUpEd portal, as the overarching philosophy is consistent with our mission of transforming lives and societies. Therefore, future pilot MOOC initiatives by DCU will be available through OpenUpEd along with other channels depending on the platform.

\section{Strategic Fit}

All of the above MOOC options have advantages and disadvantages and the only way that DCU has been able to fully evaluate their strategic fit for purpose is to review the functionality, sustainability, business models, strategic affordances, and so on, of each platform using a decision matrix.

To guide this decision process we developed a set of key questions that institutional leaders responsible for weighing up the pros and cons of different MOOC initiatives need to consider. The following questions are not intended to be inclusive of all the situated and contextual factors relevant to other institutions as they primarily reflect the strategic drivers identified from the DCU experience.

- How technically fit for purpose is the platform?

- How pedagogically fit for purpose is the platform?

- How sustainable is the business model for the platform?

- How reputable are the partners associated with the platform?

- How well is the platform suited to supporting academic readiness?

- How well does the platform support innovative forms of pedagogy?

- How strong is the pedagogical community supporting innovation through the platform?

- How well suited is the initiative to promoting the goals of outreach and wider access to higher education for all?

- What will be lost if we do nothing? What are the opportunity costs associated with the initiative?

- What are our measures of success? How will we know whether the MOOC platform has met our success criteria?

This work is licensed under a Creative Commons Attribution 4.0 International License. 
A decision matrix with different weights assigned to the above questions according to significance has helped to provide a more thorough and trustworthy evaluation of the relative merits of each MOOC option. This approach assigns a score to each question from low to high, multiplied by the respective weight, to help calculate an overall total for each MOOC platform. While there are other qualitative factors that need to be considered in reaching a decision on the most appropriate MOOC option for DCU, this type of decision matrix serves as a valuable tool for evaluating such a rapidly evolving area of innovation. In many respects the score allocated to each MOOC option in the decision matrix is less important than the discussions that have arisen through this process.

In a similar vein, we have generated valuable dialogue and matured our thinking by plotting different MOOC options on a chart in order to highlight key differences where the $x$ and $y$ axis represent specific variables. For example, Figure 3 depicts the differences we perceive between four different MOOC options according to brand awareness $(x)$ and strength of pedagogical community $(y)$. The figure below shows FutureLearn in the most desirable top right quadrant with both high brand awareness and a strong pedagogical community supporting future development. Of course, this assessment reflects a European bias as FutureLearn has yet to establish a major foothold in North America. In the case of Open2Study, the bottom left quadrant reflects the fact that this MOOC is very much an Australasian initiative but the position could change in the future. Importantly, the relative position of the MOOC platforms changes depending on the variables, especially if you select the cost of the option compared to brand awareness or the ability to make local customisations compared to the strength of the pedagogical community.

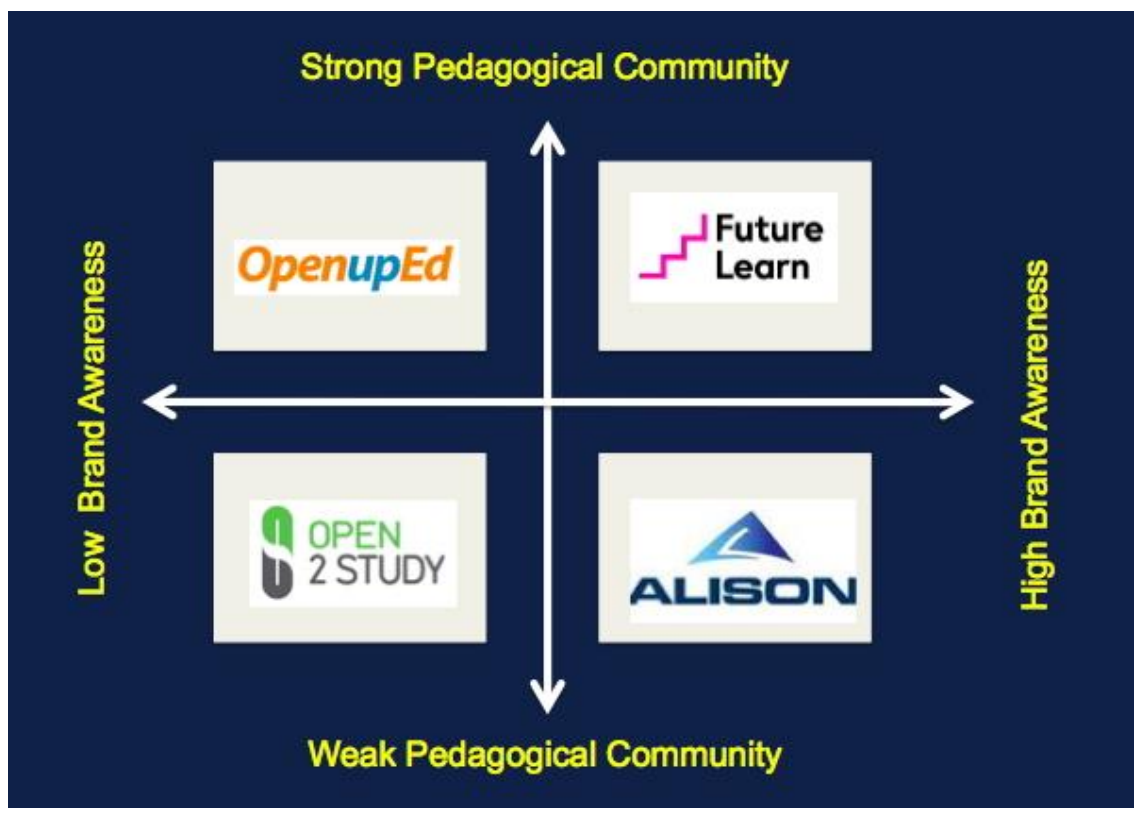

Figure 3: Example decision plot 
The key point is that by using these decision tools we have been able to better define and compare and contrast the variables that matter most to DCU. It has also become apparent through this exercise that the selection of the best strategic fit for DCU will require comprise and our strong emphasis on innovation as a driver may be best advanced through pilots and a multi-platform deployment strategy. Finally, we have learnt that in identifying key drivers and evaluating our longer-term objectives against the affordances of different MOOC platforms the sum of the whole is far more important than the individual parts (Brown \& Costello, 2015). This point serves to illustrate once again that the institutional context is crucial to deliberations about the potential benefits of micro-level MOOC initiatives which need to engage a wide range of stakeholders with differing perspectives.

\section{Conclusion}

Against the backdrop of the so-called MOOC debate, and findings of major surveys reporting institutional objectives for open educational initiatives, this paper has described some of the key drivers, deliberations, and decision points that have faced DCU in evaluating different MOOC options. It has addressed a gap in the published literature by giving an insider's perspective within a single institutional context to some of the factors that have influenced thinking about MOOCs. What is clear from this micro-level experience is that a rational for investing in MOOCs based on the "Fear Of Missing Out" (FOMO) does not provide a strong or sustainable argument for committing valuable resources to this area innovation. Any strategic decision to invest in MOOCs needs to be weighed up against the opportunity costs of pursuing other innovations, as teachers and academic leaders may be distracted from more important work. Where DCU goes from here has yet to be fully determined but there is a strong desire to learn from, and contribute to, the evolution of the MOOC movement. Put simply, DCU intends to continue to play a leading role in new models of online, blended, and flexible learning. However, the challenge of weighing up and prioritising competing institutional drivers, along with the complexity of choices facing universities in the age of the MOOC, should not be underestimated. There are significant financial and reputation risks. With this last point in mind, the particular contribution of this paper is that it offers insights into a number of strategic questions about MOOCs, which we hope may help guide future decisions in other institutions.

\section{References}

Allen, I. E., \& Seaman, J. (2015). Grade level: Tracking online education in the United States. Babson Park, MA: Babson Survey Research Group and Quahog Research Group, LLC. Retrieved from http://www.onlinelearningsurvey.com/reports/gradelevel.pdf

Allen, I. E., \& Seaman, J. (2014). Grade change: Tracking online education in the United States. Babson Park, MA: Babson Survey Research Group and Quahog Research Group, LLC. Retrieved from http://www.onlinelearningsurvey.com/reports/gradechange.pdf This work is licensed under a Creative Commons Attribution 4.0 International License. 
Barber, M., Donnelly, K., \& Rizvi, S. (2013). An avalanche is coming: Higher education and the revolution ahead. Institute for Public Policy Research. London.

Barlow, A. (2014). Just another colonist tool? In S. Krause \& C. Lowe (Eds.), Invasion of the Moocs: The Promise and Perils of Massive Open Online Courses (pp. 73-85). San Francisco: Parlor Press. Retrieved from http://www.parlorpress.com/pdf/invasion of the moocs.pdf

Brown, T. (2015). Exploring new learning paradigms - A reflection on Barber, Donnelley and Rizvi (2013): "An avalanche is coming: Higher education and the revolution ahead". International Review of Research in Open and Distributed Learning, 16 (4), 227-234.

Brown, M., \& Costello, E. (2015). MOOCs in question: Strategic insights from two institutional experiences. In D. Jansen \& A. Teixeira, A. (Eds). Position papers for European cooperation on MOOCs, European Association for Distance Teaching Universities (EADTU), 130-148. Retrieved from http://home.eadtu.eu/images/Position papers for European cooperation on MOOC s.pdf

Carson, S., Kanchanaraksa, S., Gooding, I., Mulder, F., \& Schuwer, R. (2012). Impact of opencourseware publications on higher education participation and student recruitment. The International Review of Research in Open and Distance Learning, 13(4), 19-32.

Conor, K. (2014). MOOCs, institutional policy and change dynamics in higher education. Higher Education, 68, 623-635.

Holland, F., \& Tirthali, D. (2014). MOOCs: Expectations and reality. Full report. Center for Benefit-Cost Studies of Education. Teachers College, Columbia University. Retrieved from http://cbcse.org/wordpress/wpcontent/uploads/2014/05/MOOCs Expectations and Reality.pdf

Johnson, L., Adams Becker, S., Cummins, M., Estrada, V., \& Freeman, A. (2015). 2015 NMC Technology Outlook for Higher Education in Ireland: A Horizon Project Regional Report. Austin, Texas: The New Media Consortium. Retrieved from http://www.nmc.org/publication/2015-nmc-technology-outlook-higher-education-inireland/

Krause, S., \& Lowe, C. (2014). Invasion of the MOOCs: The promise and perils of massive open online courses. San Francisco: Parlor Press. Retrieved from http://www.parlorpress.com/pdf/invasion of the moocs.pdf 
Macleod, H., Haywood, J., Woodgate, A., \& Alkhatnai, M. (2015). Emerging patterns in MOOCs: Learners, course design and directions. TechTrends, 59 (1), 56-63.

Open Education Europa. (2015). European MOOC scoreboard. Retrieved 2oth January 2015 from http://www.openeducationeuropa.eu/en/european scoreboard moocs

Rosewell, J., \& Jansen, D. (2014). The OpenupEd quality label: Benchmarks for MOOCs. International Journal for Innovation and Quality in Learning, 2(3), 67-75. Retrieved fromhttp://papers.efquel.org/index.php/innoqual/article/view/160/45

Selwyn, N., Bulfin, S., \& Pangrazio, L. (2015). Massive open online change? Exploring the discursive construction of the 'MOOC' in newspapers. Higher Education Quarterly, 1-18.

Sharples, M. (2014, May). Innovating pedagogy: New models of teaching, learning and assessment. Keynote address at the Irish Learning Technology Association Conference. Dublin.

Sharrock, G. (2015). Making sense of the MOOC debate. Journal of Higher Education Policy and Management, 37 (5), 597-609.

Weller, M., \& Anderson, T. (2013). Digital resilience in higher education. European Journal of Open, Distance and e-Learning, 16(1), 53-66. Retrieved from http://www.eurodl.org/materials/contrib/2013/Weller_Anderson.pdf

\section{Athabasca University}

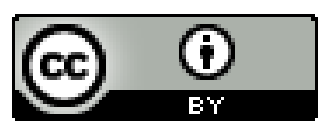

